\title{
FORMULATION AND IN-VIVO STUDY OF KETOPROFEN TABLETS PREPARED USING CHITOSAN INTERPOLYMER COMPLEXES
}

\author{
Abd El-Gawad H. Abd El-Gawad, Esmail M. Ramadan, Osama A. Soliman and \\ Rehab M. Yusif \\ Department of Pharmaceutics, Faculty of Pharmacy, Mansoura University, 35516 Mansoura, \\ Egypt
}

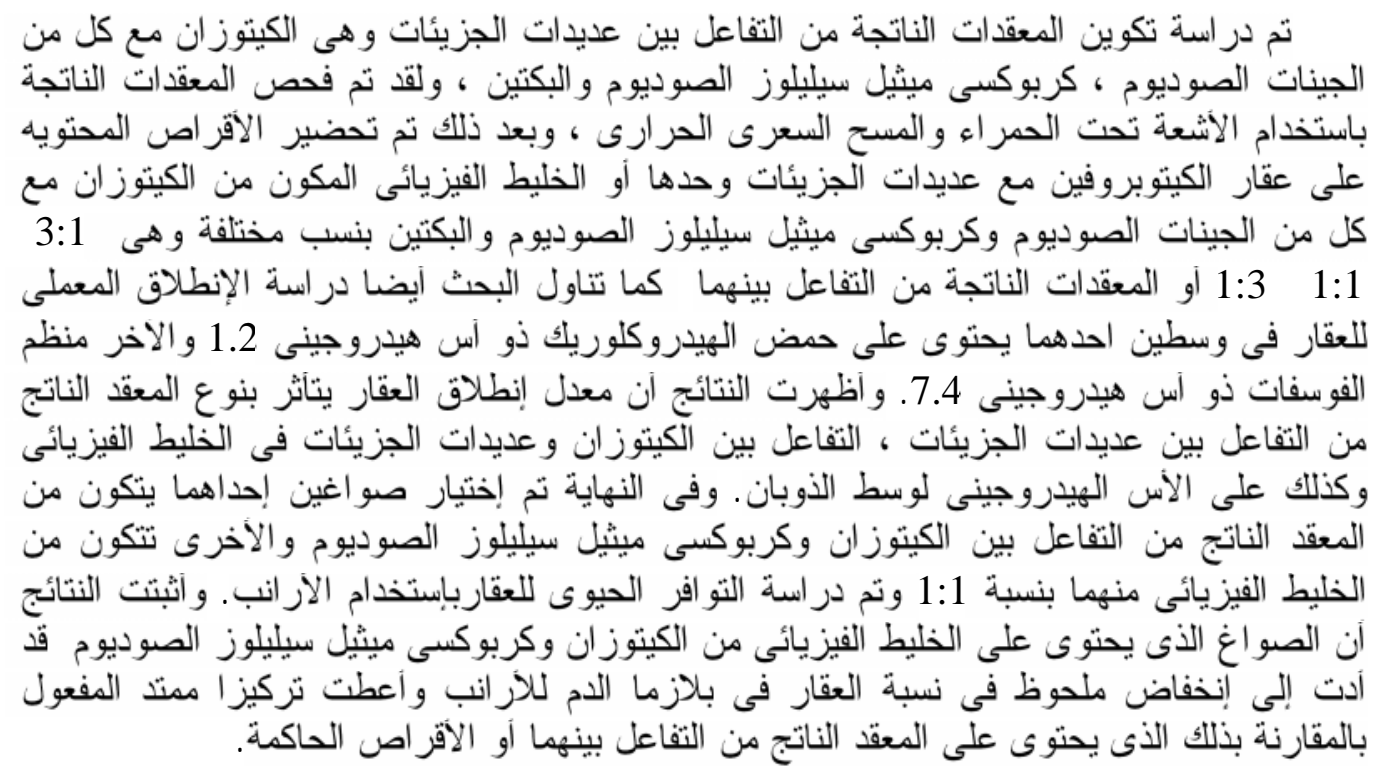

The application of interpolymer complexes (IPCs) for oral controlled drug delivery systems was tested between chitosan and various anionic polymers viz sodium alginate, sodium carboxymethylcellulose and pectin. The prepared IPCs were investigated using Fourier transform infra-red spectroscopy and differential scanning calorimetry. Ketoprofen tablets were prepared using the polymers alone, physical mixtures of chitosan with sodium alginate, sodium carboxymethylcellulose or pectin in different ratios; $1: 3,1: 1$ and $3: 1$, and the corresponding IPCs. In-vitro release studies were carried out in two dissolution media; $0.1 \mathrm{~N} \mathrm{HCl}$ of $\mathrm{pH} 1.2$ and phosphate buffer of $\mathrm{pH} 7.4$.

It was found that, chitosan - sod. carboxymethylcellulose IPC tablets showed more controlled drug release compared to that containing chitosan - sodium alginate and chitosan pectin IPCs. The dissolution rate from tablets prepared using physical mixtures of polymers were found to be dependant on the interaction between chitosan and each of the anionic polymers in the physical mixtures, their ratios and $\mathrm{pH}$ of the dissolution medium. Tablets prepared using chitosan - sod. carboxymethylcellulose physical mixture 1:1 and chitosan - sod. carboxymethylcellulose IPC were selected for the in-vivo study using albino rabbits. The results showed a lower peak plasma concentration and marked controlled release effect of drug in tablets containing the physical mixture compared to that of the IPC and the control tablets.

\section{INTRODUCTION}

It has been reported that, polyions of opposite charges interact electrostatically with each other to form interpolymer complexes (IPCs). The properties of IPCs depend on various factors including; nature and position of the ionic groups, their concentrations, proportion of opposite charges and molecular weight of the macromolecules ${ }^{1-3}$. Other factors influencing IPCs properties include $\mathrm{pH}$ of the medium, temperature and order of mixing ${ }^{4}$.

Various methods have been used to investigate interactions between polymers. The 
most commonly used techniques for characterization of IPC formation are turbidity, viscosity measurement, Fourier transform infra-red (FT-IR) and differential scanning calorimetry (DSC) $)^{5-7}$.

Chitosan is a natural, non-toxic, biodegradable and biocompatible polysaccharide that has been used in the biomedical areas in the form of wound healing material and drug delivery system. It is a very promising biomaterial for drug delivery system, however, its use in oral administration is restricted by its fast dissolution in the stomach and its limited capacity as controlled drug delivery system ${ }^{8}$. To overcome these disadvantages, many researchers have investigated the IPC of chitosan with other anionic polymers like sodium alginate, carrageenan, hyaluronate sodium, pectin and polyacrylic acid $^{9 \& 10}$ for controlled release formulations.

Moreover, it has been reported that, drug release from tablets containing physical mixtures of polymers will form in-situ polyion complexes that affords more sustained effect compared to the prepared complexes ${ }^{11 \& 12}$. Also, Bhise et al. ${ }^{13}$ have found that, minimum drug release was observed for naproxen from matrices containing physical mixture of chitosan and $\mathrm{\kappa}$-carrageenan at acidic and alkaline $\mathrm{pH}$ and this may be due to the formation of in-situ polyelectrolyte complexes that could be suitable for sustained drug delivery.

Ketoprofen [2- (3-benzoylphenyl) propionic acid] is a non-steroidal antiinflammatory drug (NSAID). It is widely used to reduce pain, inflammation and stiffness caused by several conditions such as osteoarthritis, rheumatoid arthritis or abdominal cramps associated with menstruation. Ketoprofen prepared in conventional dosage forms is rapidly and completely absorbed from the gastro-intestinal tract. After oral administration, the peak plasma concentration is attained in $1-3 \mathrm{hrs}^{14}$.

Ketoprofen may be a candidate for formulation in controlled release dosage forms due to its short half-life and its poor solubility in water, which affects its bioavailability ${ }^{15 \& 16}$. Therefore, in order to maintain therapeutic plasma levels, modified release dosage forms may be beneficial for allowing only one daily dose of the drug with consequent improvement of patient compliance ${ }^{17-19}$.

The aim of the present work, was to prepare and characterize the interpolymer complexes composed of chitosan with anionic polymers as sodium alginate, sodium carboxymethylcellulose and pectin. Also, studying the effect of the tested polymers on the dissolution rate of ketoprofen from the prepared tablets. In addition, to investigate the in-vivo performance of the drug from the selected formulae compared to the control tablets using albino rabbits.

\section{EXPERIMENTAL}

\section{Materials}

Chitosan (high molecular weight), ketoprofen and naproxen (Sigma-Aldrich Chemie, Germany), sodium alginate (BDH chemicals, Ltd, Poole, England), pectin (Winlab, U.K.), EDTA disodium salt and sodium carboxymethylcellulose (EL-Nasr Pharmaceutical Chemicals Co., Cairo, Egypt), Diethyl ether and acetonitrile HPLC grade (Scharlau Chemie S.A., European Union). Other materials are of analytical grade.

\section{Equipment}

Single punch tablet machine (ErwekaApparatebau, GmbH, Germany), tablet hardness tester (Erweka-Apparatebau, $\mathrm{GmbH}$, Germany) and Roche friabilator (ErwekaApparatebau, GmbH, Germany), UV-visible spectrophotometer (JASCO, V-530, Japan), six jars dissolution apparatus (DA-6D, India), Fourier transform infra-red spectrophotometer (Thermo Fisher Scientific, Inc., Waltham, MA, USA), Differential scanning calorimeter (Pyris 6 DSC, Perkin Elmer, USA) and High performance liquid chromatography (HPLC) (Perkin Elmer, USA).

\section{Preparation of interpolymer complexes}

Chitosan solutions $(1 \% \mathrm{w} / \mathrm{v})$ in $5 \% \mathrm{v} / \mathrm{v}$ acetic acid solution were added to sod. alginate, sod. CMC or pectin solutions in distilled water $(1 \% \mathrm{w} / \mathrm{v})$. The mixtures were incubated at $37^{\circ} \mathrm{C}$ for $24 \mathrm{hrs}$, followed by centrifugation at $5000 \mathrm{rpm}$ for $20 \mathrm{~min}$. The precipitated products were separated from the solution by centrifugation, washed with distilled water, then, dried for 2 days at 
$40^{\circ} \mathrm{C}^{9}$.The dried complexes were ground using a micronizing mill. Finally, the powders were passed through $200 \mathrm{~m}$ sieve and stored in a desiccator until used for further investigation by FT-IR and DSC.

\section{Fourier transform infra-red spectroscopy (FT-IR)}

Infra-red spectra of chitosan, sod. alginate, sod. CMC and pectin each alone, physical mixtures of chitosan with each of the previous anionic polymers and the prepared IPCs were determined. Two-mg sample was mixed with $200 \mathrm{mg}$ potassium bromide $(\mathrm{KBr})$. These mixtures were ground into fine powder, then compressed into $\mathrm{KBr}$ disc using a hydraulic press. Each $\mathrm{KBr}$ disc was scanned over a wave number region of $500-4000 \mathrm{~cm}^{-1}$ and the resolution was $4 \mathrm{~cm}^{-1}$. The characteristic bands were recorded for all samples.

\section{Differential scanning calorimetry (DSC)}

Differential scanning calorimetry used to characterize the thermal behavior of chitosan, sod. alginate, sod. CMC and pectin individually, physical mixtures of chitosan with each of the previous anionic polymers and the prepared IPCs. Temperature calibration was performed using indium as a standard (transition point: $156.60^{\circ} \mathrm{C}$ ). Samples were weighed $(10 \mathrm{mg})$ directly in uncovered aluminum pans and scanned between 30 and $450^{\circ} \mathrm{C}$ at a heating rate of $10^{\circ} \mathrm{C} / \mathrm{min}$ under constant purging of dry nitrogen at $30 \mathrm{ml} / \mathrm{min}$.

\section{Preparation of ketoprofen tablets}

Tablets weighing $200 \mathrm{mg}$, each contains $50 \mathrm{mg}$ ketoprofen were prepared by direct compression. The composition of each formula is shown in table 1 . The interpolymer complex of chitosan with sod. alginate, sod. CMC and pectin, also, their physical mixtures in different ratios $(1: 3,1: 1$ and $3: 1)$, in addition to the individual polymers were used as tablet matrices. Each of the previously mentioned powders were mixed with ketoprofen, HPMC $(5 \% \mathrm{w} / \mathrm{w}$ as a binder) and magnesium stearate $(1 \% \mathrm{w} / \mathrm{w})$.

\section{Evaluation of tablets}

The prepared tablets were evaluated for hardness value, thickness, friability percent, disintegration time and drug content uniformity according to USP XXVII ${ }^{20}$.

\section{In-vitro drug release}

The in-vitro release studies of ketoprofen from the prepared tablets were performed according to the USP $\mathrm{XXVII}^{20}$ using dissolution apparatus I. One tablet was placed in each basket and immersed in $500 \mathrm{ml}$ of dissolution medium which rotated at $50 \mathrm{rpm}$ and maintained at $37 \pm 0.5^{\circ} \mathrm{C}$. The dissolution medium was $0.1 \mathrm{~N} \mathrm{HCl}$ of $\mathrm{pH} 1.2$ or phosphate buffer of $\mathrm{pH}$ 7.4. Samples of $1 \mathrm{ml}$ were withdrawn at specified time intervals $(15,30$, $45,60,90,120,180,240,300 \& 360 \mathrm{~min})$ and the volume was compensated to the initial volume by adding fresh dissolution medium after each sampling. The samples were diluted, filtered using millipore filter $(0.45 \mu \mathrm{m})$ and spectrophotometrically analyzed at $260 \mathrm{~nm}$. The experiment was carried out in triplicate and the data of in-vitro release were expressed as mean \pm standard deviation $( \pm$ S.D $)$.

\section{Kinetic release study}

The mechanism of ketoprofen release from the prepared tablets during dissolution study in $0.1 \mathrm{~N} \mathrm{HCl}$ of $\mathrm{pH} 1.2$ and in phosphate buffer of $\mathrm{pH} 7.4$ was determined using Korsmeyer-Peppas equation ${ }^{21}$.

\section{In-vivo study}

\section{Selected ketoprofen formulae}

The selected ketoprofen formulae for bioavailability study were; tablets containing physical mixture of chitosan - sod. CMC 1:1 (CSC2) and chitosan - sod. CMC IPC (CSC4). They were selected on the basis of acceptable physical characteristics and drug release. They were compared to control tablet (L) which contains $50 \mathrm{mg}$ ketoprofen and lactose monohydrate.

\section{Study design}

Male albino rabbits weighing $2.0-2.5 \mathrm{Kg}$ were randomly selected for the bioavailability study. The animals were divided into three groups, each group includes six rabbits which received one of the tested formulae. Twelve hours before drug administration, food was withdrawn from the rabbits until 24 hrs postdosing, while, water was available for rabbits throughout the study. The tablets were administered to rabbits using a balling gun. Blood samples $(1 \mathrm{ml})$ were withdrawn from the ear vein before dosing (zero time) and at time intervals of $0.5,1,2,4,6,8,10,12$ and $24 \mathrm{hrs}$ 
Table 1: Composition of ketoprofen tablets prepared using chitosan IPCs and physical mixtures with different anionic polymers.

\begin{tabular}{|c|c|c|c|c|c|c|c|c|c|c|}
\hline \multirow{3}{*}{ Formulae } & \multirow{3}{*}{$\begin{array}{l}\text { Formulae } \\
\text { Code }\end{array}$} & \multirow{3}{*}{$\begin{array}{l}\text { Drug } \\
(\mathrm{mg})\end{array}$} & \multicolumn{7}{|c|}{$\begin{array}{l}\text { The quantity of ingredients in each } \\
\text { tablet (mg) }\end{array}$} & \multirow{3}{*}{$\begin{array}{c}\text { Total } \\
\text { Weight } \\
\text { of } \\
\text { tablet }\end{array}$} \\
\hline & & & \multicolumn{4}{|c|}{ Polymer } & \multicolumn{3}{|c|}{ Interpolymer complex (IPC) } & \\
\hline & & & Chitosan & $\begin{array}{l}\text { Sod. } \\
\text { alginate }\end{array}$ & $\begin{array}{l}\text { Sod. } \\
\text { CMC }\end{array}$ & Pectin & $\begin{array}{l}\text { Chitosan } \\
\text { - sod. } \\
\text { alginate } \\
\text { IPC }\end{array}$ & $\begin{array}{l}\text { Chitosan- } \\
\text { sod. } \\
\text { CMC } \\
\text { IPC }\end{array}$ & $\begin{array}{l}\text { Chitosan- } \\
\text { pectin } \\
\text { IPC }\end{array}$ & \\
\hline Chitosan & $\mathrm{C}$ & 50 & 138 & & & & & & & 200 \\
\hline Sod. alginate & SA & 50 & & 138 & & & & & & 200 \\
\hline Sod. CMC & $\mathrm{SC}$ & 50 & & & 138 & & & & & 200 \\
\hline Pectin & $\mathrm{P}$ & 50 & & & & 138 & & & & 200 \\
\hline $\begin{array}{c}\text { Chitosan : } \\
\text { sod. alginate } \\
(1: 3)\end{array}$ & CSA1 & 50 & 34.5 & 103.5 & & & & & & 200 \\
\hline $\begin{array}{l}\text { Chitosan : } \\
\text { sod. alginate } \\
(1: 1)\end{array}$ & CSA2 & 50 & 69 & 69 & & & & & & 200 \\
\hline $\begin{array}{c}\text { Chitosan: } \\
\text { sod. alginate } \\
(3: 1)\end{array}$ & CSA3 & 50 & 103.5 & 34.5 & & & & & & 200 \\
\hline $\begin{array}{c}\text { Chitosan: } \\
\text { sod. alginate } \\
\text { IPC } \\
\end{array}$ & CSA4 & 50 & & & & & 138 & & & 200 \\
\hline $\begin{array}{c}\text { Chitosan : } \\
\text { sod. CMC } \\
(1: 3) \\
\end{array}$ & CSC1 & 50 & 34.5 & & 103.5 & & & & & 200 \\
\hline $\begin{array}{c}\text { Chitosan : } \\
\text { sod. CMC } \\
(1: 1)\end{array}$ & $\mathrm{CSC} 2$ & 50 & 69 & & 69 & & & & & 200 \\
\hline $\begin{array}{c}\text { Chitosan : } \\
\text { sod. CMC } \\
(3: 1)\end{array}$ & CSC3 & 50 & 103.5 & & 34.5 & & & & & 200 \\
\hline $\begin{array}{c}\text { Chitosan : } \\
\text { sod. CMC } \\
\text { IPC } \\
\end{array}$ & CSC4 & 50 & & & & & & 138 & & 200 \\
\hline $\begin{array}{c}\text { Chitosan : } \\
\text { pectin } \\
(1: 3) \\
\end{array}$ & $\mathrm{CP} 1$ & 50 & 34.5 & & & 103.5 & & & & 200 \\
\hline $\begin{array}{c}\text { Chitosan : } \\
\text { pectin } \\
(1: 1)\end{array}$ & $\mathrm{CP} 2$ & 50 & 69 & & & 69 & & & & 200 \\
\hline $\begin{array}{c}\text { Chitosan : } \\
\text { pectin } \\
(3: 1) \\
\end{array}$ & $\mathrm{CP} 3$ & 50 & 103.5 & & & 34.5 & & & & 200 \\
\hline $\begin{array}{c}\text { Chitosan : } \\
\text { pectin } \\
\text { IPC } \\
\end{array}$ & $\mathrm{CP} 4$ & 50 & & & & & & & 138 & 200 \\
\hline
\end{tabular}


after administration. EDTA disodium salt was used as an anticoagulant. Plasma was separated by centrifugation at $5000 \mathrm{rpm}$ for $10 \mathrm{~min}$, frozen and stored at $-20^{\circ} \mathrm{C}$ until used.

\section{HPLC analysis for ketoprofen in rabbit's plasma}

The plasma samples were analyzed using validated HPLC method described by Corveleyn et l. $^{22}$. The mobile phase was a mixture of $0.05 \mathrm{M}$ phosphate buffer of $\mathrm{pH} 7.0$ and acetonitrile in ratio of $84: 16 \mathrm{v} / \mathrm{v}$, respectively. A solution of $50 \mu \mathrm{g} / \mathrm{ml}$ naproxen in the same mobile phase was used as an internal standard. The rabbit plasma samples were thawed at room temperature, then, for each $0.5 \mathrm{ml}$ of plasma sample, $200 \mu \mathrm{l}$ of naproxen solution in the mobile phase (50 $\mu \mathrm{g} / \mathrm{ml}$ ) was added as an internal standard, then acidified with $1 \mathrm{ml}$ of $1 \mathrm{M}$ phosphate buffer of $\mathrm{pH}$ 2.0. After that, the samples were extracted with diethyl ether $(5 \mathrm{ml})$, vortexed for $1 \mathrm{~min}$ and centrifuged for $10 \mathrm{~min}$ at $5000 \mathrm{rpm}$. The upper organic phase was separated and evaporated to dryness at $40^{\circ} \mathrm{C}$. The dry residue was dissolved in $0.5 \mathrm{ml}$ of mobile phase and the produced solution was filtered through a millipore filter $(0.22 \mu \mathrm{m})$ and $20 \mu \mathrm{l}$ of the filtrate was injected into the loop of HPLC apparatus. The mobile phase used was pumped at a flow rate $1.5 \mathrm{ml} / \mathrm{min}$, using $\mathrm{U} . \mathrm{V}$ detector at $258 \mathrm{~nm}$.

\section{Pharmacokinetic parameters}

The maximum plasma concentration $\left(\mathrm{C}_{\max }\right)$ and the time required to reach maximum plasma concentration $\left(\mathrm{T}_{\max }\right)$ after oral administration were directly determined from the plasma concentration-time curves. Also, the area under the plasma concentration-time curve from 0 to $24 \mathrm{hrs}$ (AUC ${ }_{0-24}$ ) was calculated using trapezoidal rule. All results are represented as means $\pm \mathrm{SD}$.

\section{Statistical analysis}

Comparison between the pharmacokinetic parameters of ketoprofen following the oral administration of three tested formulae was carried out using ANOVA test followed by Tukey Kramer test for comparison. The test was performed using instate 2-computer program (Graphpad software Inc., V2, San Diego, CA, U.S.A.).

\section{RESULTS AND DISCUSSION}

\section{Fourier transform infra-red spectroscopy (FT-IR)}

The FT-IR spectra of chitosan, sod. alginate, sod. CMC and pectin individually, physical mixtures of chitosan with each of sod. alginate, sod. CMC and pectin and their IPCs are shown in figures 1-3. The FT-IR spectrum of chitosan shows two bands at 1649 \& $1587 \mathrm{~cm}^{-1}$. The band at $1649 \mathrm{~cm}^{-1}$ is due to the carbonyl stretching vibration of the secondary amide group, while that at $1587 \mathrm{~cm}^{-1}$ is due to $\mathrm{N}-\mathrm{H}$ bending vibration of amino group, because it is obtained from partial $N$ deacetylation of chitin $^{23}$.

The FT-IR spectra of chitosan, sod. alginate, their physical mixture and the corresponding IPC are shown in figure 1. Sod. alginate spectrum showed an absorption bands at 1617 and $1418 \mathrm{~cm}^{-1}$ which corresponding to asymmetric and symmetric stretching vibration of carboxylate group ${ }^{24 \& 25}$. Chitosan - sod. alginate IPC spectrum showed a shift of chitosan absorption bands to lower wave number at 1644 and $1570 \mathrm{~cm}^{-1}$, while, the physical mixture showed only one band at 1620 $\mathrm{cm}^{-1}$. This shift was due to the formation of ionic bonds between the protonated amino group of chitosan and carboxylate group of sod. alginate which confirm the formation of IPC. These results were in agreement with that obtained by Sankalia et al., Abdelbary \& Tadros, Moustafine et al. and Shu et al. ${ }^{7,9,26 \& 27}$.

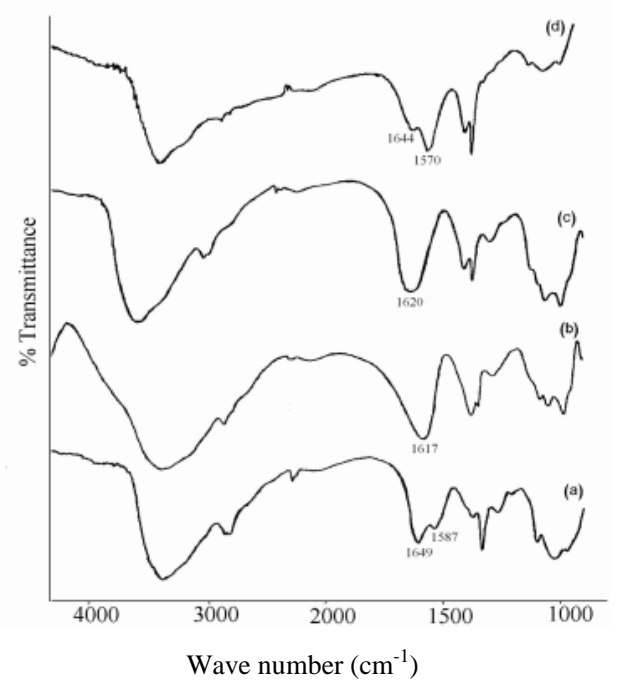

Fig. 1: FT-IR spectra of chitosan, sod. alginate, their physical mixture and IPC.
(a) Chitosan
(b) Sod. alginate
(c) Physical mixture 1:1
(d) IPC 1:1 
Also, the FT-IR spectrum of the chitosan sod. CMC IPC showed a characteristic broad band at $1602 \mathrm{~cm}^{-1}$ which is different from that of the individual polymers or the physical mixture spectra. Furthermore, the band at 1434 $\mathrm{cm}^{-1}$ which was due to symmetric stretching of carboxylate group of sod. CMC was reduced and shifted to lower wave number at $1400 \mathrm{~cm}^{-1}$ in the IPC spectrum due to its interaction with the amino group of chitosan as shown in figure 2. Rosca $e t a l .^{28}$ stated that, the shift of the amino band to $1602 \mathrm{~cm}^{-1}$ is expected, since, a complex formation occurs through the electrostatic interaction of the cationic groups from chitosan with the anionic ones from sod. CMC.

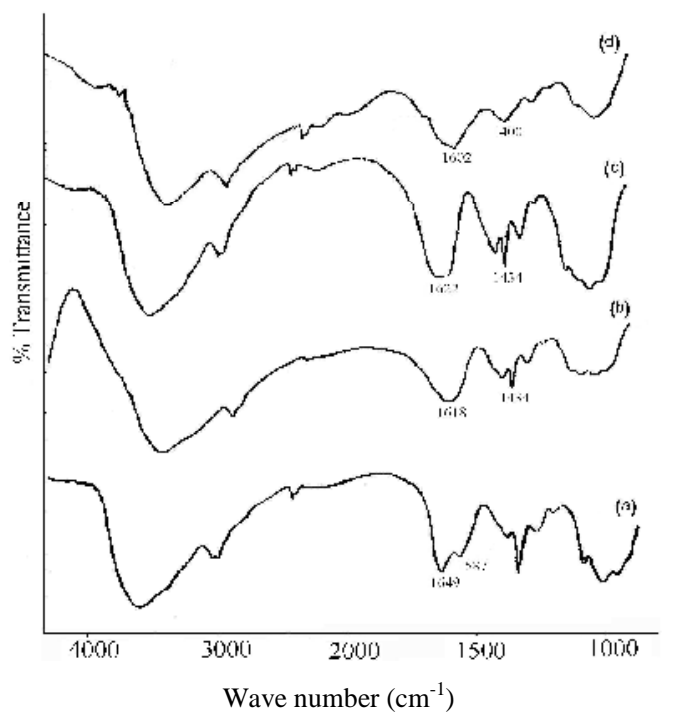

Fig. 2: FT-IR spectra of chitosan, sod. CMC, their physical mixture and IPC.
(a) Chitosan
(b) Sod. CMC
(c) Physical mixture 1:1
(d) IPC 1:1

The FTIR spectrum of pectin (Fig. 3), shows two bands at 1741 and $1632 \mathrm{~cm}^{-1}$, that could be related to $\mathrm{C}=\mathrm{O}$ stretching of ester and carboxyl groups, respectively ${ }^{29}$. However, the spectrum of chitosan - pectin IPC (Fig. 3) showed a shift of pectin bands to lower wave numbers at 1730 and $1624 \mathrm{~cm}^{-1}$ compared to their physical mixture which indicated the evidence of interaction between the amino groups of chitosan and carboxyl groups of pectin. These results confirmed the IPC formation between chitosan and pectin and were similar to that obtained by Rashidova et al. $^{30}$.

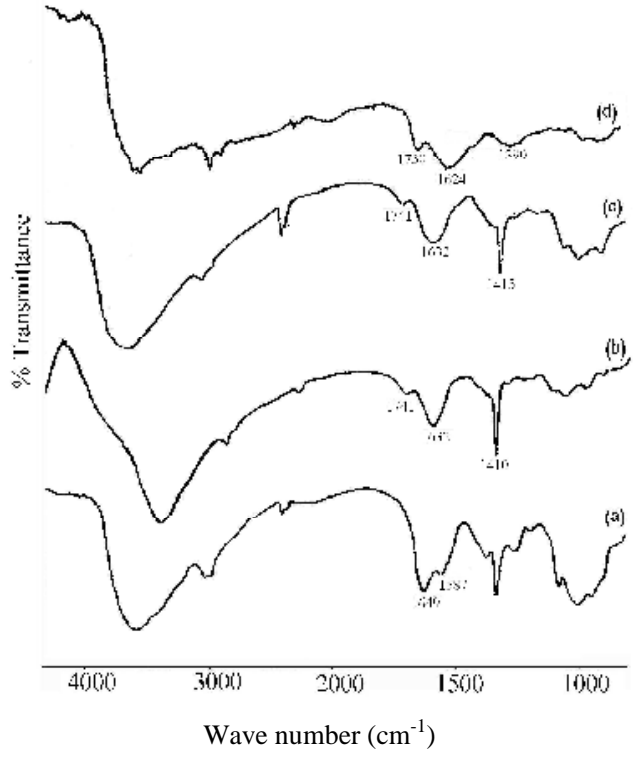

Fig. 3: FT-IR spectra of chitosan, pectin, their physical mixture and IPC.
(a) Chitosan
(b) Pectin
(c) Physical mixture 1:4
(d) IPC 1:4

\section{Differential scanning calorimetry (DSC)}

Thermograms of DSC were performed in order to investigate the possible solid-state interactions between the components. The figures of thermal analysis of chitosan, sod. alginate, sod. CMC and pectin, individually, their physical mixtures and IPCs are shown in figures 4-6. The thermogram of chitosan showed a broad endothermic peak at $80.39^{\circ} \mathrm{C}$, due to the polymer dehydration, followed by a second exothermic peak at $310^{\circ} \mathrm{C}$. Similar results were obtained by Khalid et al. and Borges et al. ${ }^{3132}$. The thermograms of sod. alginate, sod. CMC and pectin showed endothermic peaks at $89.49,86.64$ and $89.18^{\circ} \mathrm{C}$, in addition to exothermic ones at 261 , 310 and $238^{\circ} \mathrm{C}$, respectively.

Endothermic peaks are corresponding to the loss of water associated with the hydrophilic groups of polymers which have a strong affinity for water and their hydration properties depend on their molecular structures ${ }^{33 \& 34}$. While, the exothermic ones referred to the degradation of polyelectrolytes due to thermal decomposition and depolymerization reactions most probably to the partial decarboxylation of the carboxylic groups and oxidation reactions ${ }^{35 \& 36}$.

The DSC thermograms of chitosan, sod. alginate, chitosan - sod. alginate physical 
mixture and their IPCs are shown in figure 4. It is obvious that, the thermogram of chitosan sod. alginate physical mixture showed two exothermic peaks at 265 and $310^{\circ} \mathrm{C}$ that resulted from individual contribution of sod. alginate and chitosan, respectively. However, the thermogram of IPC, showed a new exothermic one at $287.5^{\circ} \mathrm{C}$, which assigned to the formation of an ionic pair between the carboxylate group $\left(-\mathrm{COO}^{-}\right)$of sod. alginate and ammonium group $\left(\mathrm{NH}_{3}{ }^{+}\right)$of chitosan. In addition to the disappearance of the degradation exothermic peaks of both chitosan and sod. alginate. These results were in agreement with Sankalia et al. and OstrowskaCzubenko \& Gierszewska-Druzyn'ska ${ }^{7 \& 37}$. The same behaviour was also observed in case of chitosan - sod. CMC IPC (Fig. 5) which showed an exothermic peak at $260^{\circ} \mathrm{C}$ with complete disappearance of chitosan or sod. CMC exothermic peaks.

The DSC thermogram of chitosan - pectin physical mixture showed two exothermic peaks at 240 and $308^{\circ} \mathrm{C}$, that correspond to pectin and chitosan, respectively (Fig. 6). However, the chitosan - pectin IPC thermogram showed a shift of the exothermic peaks to lower temperature at $213^{\circ} \mathrm{C}$ and $260^{\circ} \mathrm{C}$ which indicated the interactions between the two polymers and may be considered as a proof of their complexation. Similar results were obtained for chitosan and pectin by Ghaffari et al. $^{29}$.

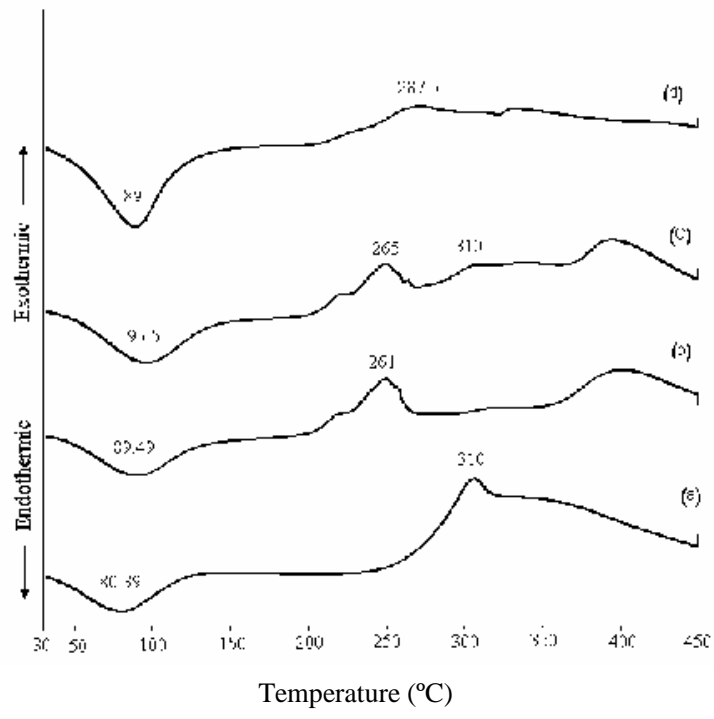

Fig. 4: DSC thermograms of chitosan, sod. alginate, their physical mixture and IPC.
(a) Chitosan
(b) Sod. alginate
(c) Physical mixture 1:1
(d) IPC 1:1

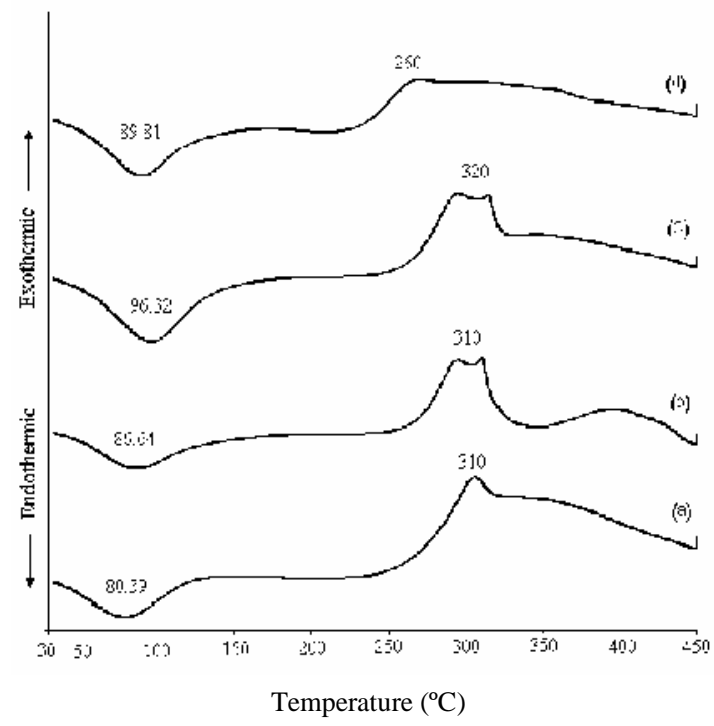

Fig. 5: DSC thermograms of chitosan, sod. CMC, their physical mixture and IPC.
(a) Chitosan
(b) Sod. CMC
(c) Physical mixture 1:1
(d) IPC 1:1

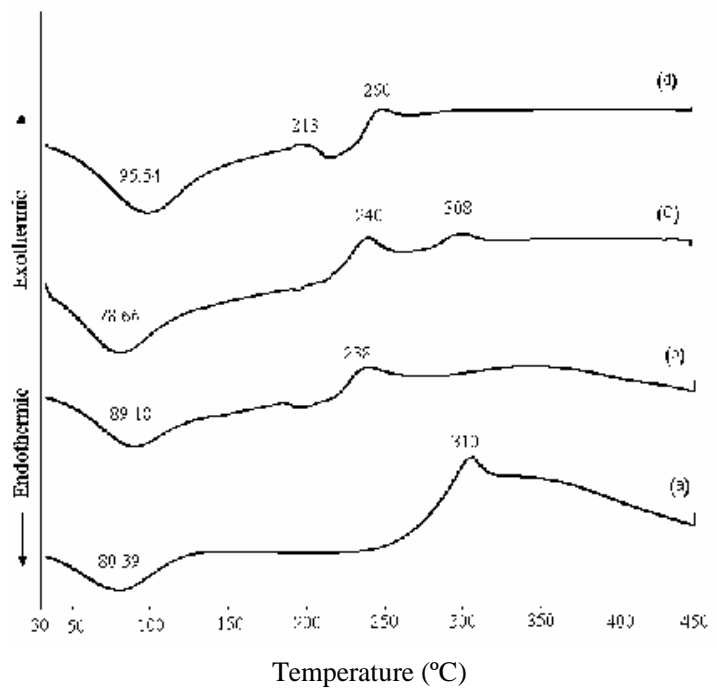

Fig. 6: DSC thermograms of chitosan, pectin their physical mixture and IPC.
(a) Chitosan
(b) Pectin
(c) Physical mixture 1:4
(d) IPC 1:4

\section{Physical properties of ketoprofen tablets}

The physical properties of ketoprofen tablets are shown in table 2. The tablet formulae (except pectin tablets) showed acceptable physical properties. The drug content of the prepared tablets was within the requirements of USP XXVII ${ }^{20}$.

\section{In-vitro drug release}

The release of ketoprofen from the prepared tablets was studied using $0.1 \mathrm{~N} \mathrm{HCl}$ 
Table 2: Physical properties of ketoprofen tablets.

\begin{tabular}{|c|c|c|c|c|c|}
\hline $\begin{array}{l}\text { Formulae } \\
\text { Code }\end{array}$ & $\begin{array}{c}\text { Drug content } \\
(\%)\end{array}$ & $\begin{array}{c}\text { Tablet } \\
\text { Thickness } \\
(\mathrm{mm})\end{array}$ & $\begin{array}{c}\text { Friability } \\
(\%)\end{array}$ & $\begin{array}{c}\text { Hardness } \\
(\mathrm{Kg})\end{array}$ & $\begin{array}{c}\text { Disintegration } \\
\text { time } \\
(\mathrm{min} .)\end{array}$ \\
\hline L & $99.76 \pm 1.53$ & $2.1 \pm 0.07$ & 0.85 & $7.25 \pm 1.5$ & $15.23 \pm 0.45$ \\
\hline C & $100.91 \pm 3.12$ & $2.62 \pm 0.07$ & 0.34 & $7.66 \pm 0.72$ & $>360$ \\
\hline SA & $102 \pm 6.08$ & $2.23 \pm 0.47$ & $\underline{0.21}$ & $7.75 \pm 1.14$ & $>360$ \\
\hline SC & $91.08 \pm 4.86$ & $2.35 \pm 0.02$ & 0.59 & $8.75 \pm 0.66$ & $>360$ \\
\hline P & $103.3 \pm 2.2$ & $2.36 \pm 0.047$ & $\underline{1.20}$ & $4.75 \pm 0.60$ & $25.78 \pm 1.2$ \\
\hline CSA1 & $97.68 \pm 4.63$ & $2.45 \pm 0.03$ & 0.49 & $7.83 \pm 0.62$ & $>360$ \\
\hline CSA2 & $98.55 \pm 1.41$ & $2.38 \pm 0.09$ & 0.57 & $7.5 \pm 0.25$ & $>360$ \\
\hline CSA3 & $98.49 \pm 3.07$ & $2.39 \pm 0.04$ & 0.58 & $7.8 \pm 1.14$ & $>360$ \\
\hline CSA4 & $97.69 \pm 2.48$ & $2.5 \pm 0.04$ & 0.95 & $5.98 \pm 0.62$ & $12.02 \pm 0.03$ \\
\hline CSC1 & $100.32 \pm 5.18$ & $2.37 \pm 0.02$ & 0.26 & $\underline{8.87} \pm 0.66$ & $129.56 \pm 1.2$ \\
\hline CSC2 & $94.95 \pm 5.46$ & $2.4 \pm 0.03$ & 0.44 & $8.12 \pm 0.96$ & $>360$ \\
\hline CSC3 & $97.49 \pm 2.07$ & $2.5 \pm 0.03$ & 0.48 & $8.06 \pm 0.96$ & $>360$ \\
\hline CSC4 & $99.69 \pm 3.58$ & $2.48 \pm 0.03$ & 0.85 & $6.18 \pm 0.5$ & $>360$ \\
\hline CP1 & $99.4 \pm 2.6$ & $2.4 \pm 0.03$ & 0.95 & $5.56 \pm 0.28$ & $35.67 \pm 1.06$ \\
\hline CP2 & $97.5 \pm 1.63$ & $2.37 \pm 0.06$ & 0.61 & $6.16 \pm 0.57$ & $36.74 \pm 1.60$ \\
\hline CP3 & $100 \pm 2.1$ & $2.52 \pm 0.08$ & 0.24 & $6.68 \pm 0.42$ & $140.09 \pm 1.06$ \\
\hline CP4 & $95.7 \pm 1.37$ & $2.46 \pm 0.04$ & 0.73 & $6.25 \pm 0.38$ & $16.98 \pm 0.08$ \\
\hline
\end{tabular}

of $\mathrm{pH} 1.2$ and phosphate buffer of $\mathrm{pH} 7.4$ as dissolution media. The tested polymers not interfere with the analysis of ketoprofen in the drug release studies because there were no significant peaks for the used polymers observed in the UV range from 200 to $400 \mathrm{~nm}$ using $0.1 \mathrm{~N} \mathrm{HCl}$ of $\mathrm{pH} 1.2$ and phosphate buffer of $\mathrm{pH} 7.4$ as blank.

To study the effect of the tested polymers on the release of ketoprofen from matrix tablets, a control tablet using lactose has been prepared and used for comparison. The release profiles of ketoprofen from this control tablets showed that, $100 \%$ of the drug was released after $1 \mathrm{hr}$ in phosphate buffer of $\mathrm{pH} 7.4$, while $86.66 \%$ of the drug was released after $6 \mathrm{hrs}$ in $0.1 \mathrm{~N} \mathrm{HCl}$ as shown in figures (7-12). These results may be due to that, ketoprofen is a weak acidic drug $\left(\mathrm{pK}_{\mathrm{a}}=5.02-5.937\right)$ and its solubility is $\mathrm{pH}$ dependant which increases rapidly at $\mathrm{pH}$ values higher than the drug $\mathrm{pK}_{\mathrm{a}}$ value. The solubility of the drug was previously determined by EL-Gibaly ${ }^{38}$ and was found to be 0.1332 and $7.415 \mathrm{mg} / \mathrm{ml}$ in $(\mathrm{pH} 1.2)$ and $(\mathrm{pH}$ 7.4), respectively.

\section{Chitosan - sodium alginate tablets}

The release profiles of ketoprofen from chitosan - sod. alginate matrix tablets in $0.1 \mathrm{~N}$ $\mathrm{HCl}$ of $\mathrm{pH} 1.2$ are shown in figure 7. It is obvious from the figure that, chitosan tablets produced minimal drug release especially during the first $3 \mathrm{hrs}$ (only 5.58\%). This retardation from chitosan tablets may be due to the low solubility of drug in acidic medium ${ }^{39}$.

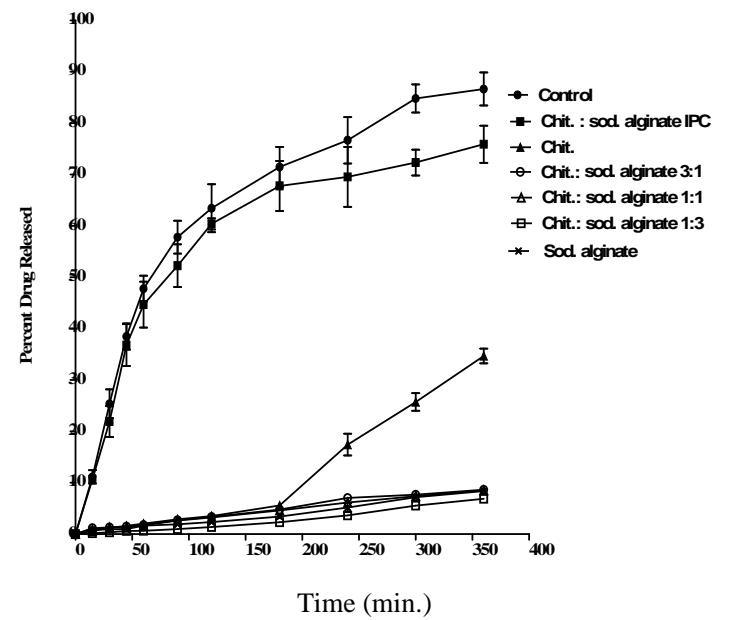

Fig. 7: In-vitro release profiles of ketoprofen from chitosan - sod. alginate tablets in $0.1 \mathrm{~N} \mathrm{HCl}$ of $\mathrm{pH} 1.2$. 
In addition to the high molecular weight of chitosan used ${ }^{40}$. Moreover, chitosan is soluble in dilute aqueous acidic solution $(\mathrm{pH}<6.5)$ and forms a gel at this acidic $\mathrm{pH}$ values, the viscosity of the produced gel increases as molecular weight or amount of polymer increase $^{41-43}$.

Drug diffusion through this gel layer and erosion of it may be regarded as the reason for further drug release occurring in $0.1 \mathrm{~N} \mathrm{HCl}$, and hence, the percent drug release increased uptill $34.68 \%$ after $6 \mathrm{hrs}$. On the other hand, the percent drug released from sod. alginate tablets was $9.13 \%$ after $6 \mathrm{hrs}$. This was explained by Dentini et al. ${ }^{44}$ who stated that, sod. alginate is converted into an insoluble alginic acid at $\mathrm{pH}<3$ and undergo a process of association, resulting in the formation of a thick network of inter- and intramolecular hydrogen bonds which responsible for the retardation of drug release.

However, chitosan - sod. alginate IPC tablets exhibited rapid release pattern $(75.9 \%$ of drug was released after $6 \mathrm{hrs}$ ), such results may be due to the fast disintegration of tablets. These results were in agreement with that of Satoh et al. and Tapia et al. ${ }^{5 \& 45}$. While, tablets containing chitosan - sod. alginate physical mixtures showed minimal drug release compared to chitosan - sod. alginate IPC tablets where $6.88,8.38 \& 8.64 \%$ of drug were released after 6 hrs from chitosan - sod. alginate physical mixtures $1: 3,1: 1$ and $3: 1$, respectively. Gonza'lez-Rodri'guez et al. $^{46}$, stated that, at acidic $\mathrm{pH}$, sod. alginate is converted into the insoluble form of alginic acid which responsible for the low rate of release and it is also hindered by positively charged groups of chitosan that strongly interact with alginate and both reducing the drug release.

Moreover, Bhise et al. ${ }^{47}$ found that, after compression of a mixture of naproxen sodium loaded chitosan particles and $\mathrm{k}$-carrageenan into tablets, the interaction between oppositely charged $\kappa$-carrageenan and chitosan leads to relatively higher gel strength, which is proportional to the ability to retard the drug release at acidic $\mathrm{pH}$.

The in-vitro release profiles of ketoprofen from chitosan - sod. alginate tablets in phosphate buffer of $\mathrm{pH} 7.4$ are shown in figure 8. From the figure, it is obvious that, tablets containing chitosan-alginate IPC showed rapid release of the drug $(100 \%$ of the drug was released after $1 \mathrm{hr}$ ) due to their disintegration as in case of $0.1 \mathrm{~N} \mathrm{HCl}$. Also, chitosan tablets showed rapid drug release where $100 \%$ of the drug was released after 2 hrs (Fig. 8). This is may be due to the weak gel forming ability and rapid disintegration characteristics of chitosan at this $\mathrm{pH}^{10 \& 48}$.

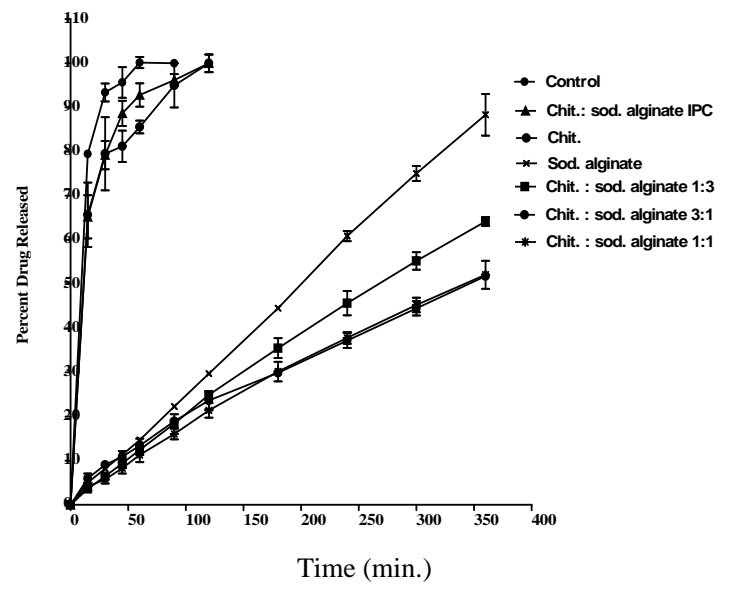

Fig. 8: In-vitro release profiles of ketoprofen from chitosan - sod. alginate tablets in phosphate buffer of $\mathrm{pH} 7.4$.

On the other hand, the percent drug release after $6 \mathrm{hrs}$ from alginate tablets in phosphate buffer $(88.33 \%)$ was greater than in acidic medium. This may be due to the solubility of alginate at that $\mathrm{pH}$ resulting in a viscous gel as alginate tablets hydrated and swelled on contact with the aqueous medium and a gel layer was formed immediately around the tablet. Then, erosion of this gel layer occurred leading to an increase of drug release $^{49}$.

The comparison of ketoprofen release performance from tablets containing chitosan sod. alginate physical mixtures in phosphate buffer of pH 7.4 (Fig. 8), showed that, the drug release from these tablets was significantly lower $(\mathrm{P}<0.05)$ compared to chitosan, sodium alginate and IPC tablets. Where, 64.17, $52.1 \&$ $51.8 \%$ of the drug were released after $6 \mathrm{hrs}$ from chitosan - sod. alginate physical mixture of ratio; $1: 3,1: 1 \& 3: 1$, respectively.

These results confirmed complex formation between chitosan and sod. alginate after penetration of the dissolution medium into the tablet. Satoh et $a l .{ }^{45}$ stated that, tablets prepared using physical mixture of polymers 
could promote IPC formation following penetration of dissolution medium into the tablet during dissolution process and this may explain why the original shape of the tablets was maintained during the dissolution process. Also, Tapia et al. ${ }^{50}$, stated that, slow drug release was obtained from tablets containing chitosan - alginate physical mixture when the $\mathrm{pH}$ changes from 5.52 to 8.72 as the drug release from the matrix is controlled by IPC formation.

\section{Chitosan - sodium CMC tablets}

The influence of $\mathrm{pH}$ of dissolution medium on the release profiles of ketoprofen from chitosan - sod. CMC tablets is shown in figures $9 \& 10$. Drug release from sod. CMC tablets in $0.1 \mathrm{~N} \mathrm{HCl}$ of $\mathrm{pH} 1.2$ showed slow drug release pattern similar to that from sod. alginate matrix tablets, where only $16.21 \%$ of the drug was released after 6 hrs (Fig. 9). ELKamel et $a l .{ }^{51}$ stated that, the ionization of carboxylic group of sod. CMC $\left(\mathrm{pK}_{\mathrm{a}}=3\right)$ decreases at acidic $\mathrm{pH}$, this affects polymer chain and the polymer network structure becomes tighter, therefore, the release rate is expected to be slower, in addition to the acidic nature of the drug.

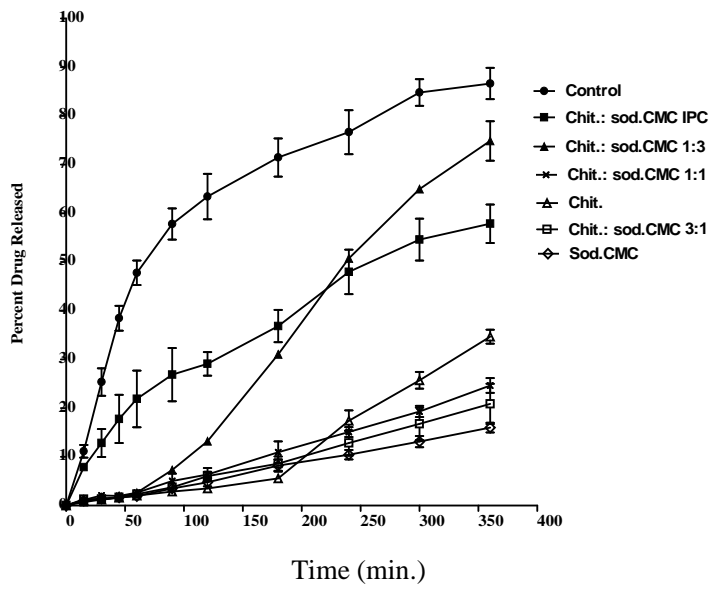

Fig. 9: In-vitro release profiles of ketoprofen from chitosan - sod. CMC tablets in $0.1 \mathrm{~N} \mathrm{HCl}$ of pH 1.2.

From the obtained data, it is clear that, the percent drug released after $6 \mathrm{hrs}$ from tablets containing chitosan - sod. CMC IPC was $57.86 \%$. However, these percent were $20.88 \&$ $24.66 \%$ from tablets containing chitosan - sod. CMC physical mixture of ratio $3: 1 \& 1: 1$, respectively, which were significantly lower than that from tablets containing chitosan or chitosan - sod. CMC IPC tablets $(\mathrm{P}<0.001)$, moreover, no disintegration of these tablets was observed during the dissolution process, that may be due to the persistent gel layer surrounding the tablets ${ }^{52}$. These results were in agreement with EL-Kamel et al. ${ }^{53}$, who found that, by incorporation of sod. CMC in tablets containing mixture of chitosan and sod. alginate, the release of metronidazole was retarded in acidic medium due to the ionic interaction between chitosan and sod. CMC and no disintegration of tablets occurred.

On the other hand, tablets containing chitosan-sod. CMC physical mixture of ratio 1:3 showed a different behavior where, a minimal drug release was observed in the first two hours followed by increasing the percent drug released till reached $74.86 \%$ after $6 \mathrm{hrs}$ which may be due to their disintegration.

The release profiles of ketoprofen from chitosan - sod. CMC tablets in phosphate buffer of $\mathrm{pH} 7.4$ are shown in figure 10 . Tablets contain sod. CMC followed the same behavior as sod. alginate tablets because of solubility of sod. CMC in phosphate buffer; thus, the drug release was more rapid in the buffer than in $0.1 \mathrm{~N} \mathrm{HCl}(81.33 \%$ was released after $6 \mathrm{hrs}$ ). From the obtained data, it is clear that, the percent drug released after $6 \mathrm{hrs}$ from tablets containing chitosan - sod. CMC IPC was $71.23 \%$, however, those containing different ratios of chitosan - sod. CMC physical mixtures significantly lowered $(\mathrm{P}<0.0001)$ the drug release as compared to chitosan, sod. CMC or IPC tablets, where, $62.28,64.26$ and $53.37 \%$ of the drug were released after $6 \mathrm{hrs}$ from chitosan - sod. CMC physical mixtures tablets of ratios; 1:1, 3:1 and 1:3 respectively.

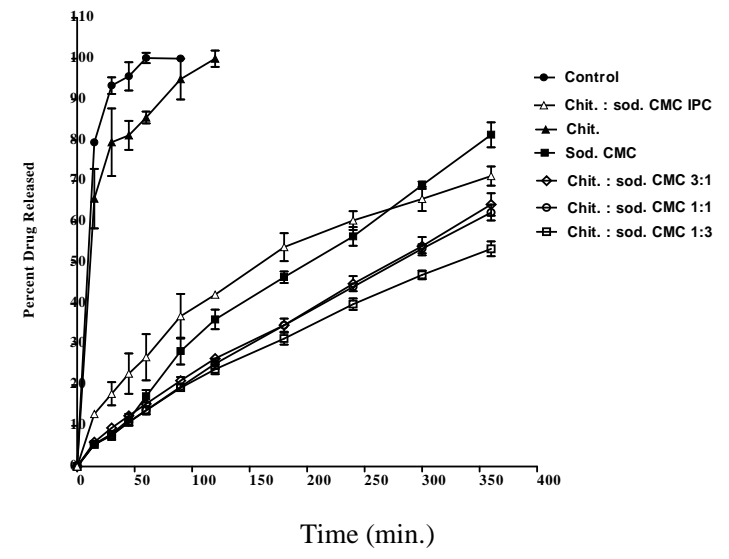

Fig. 10: In-vitro release profiles of ketoprofen from chitosan - sod. CMC tablets in phosphate buffer of $\mathrm{pH} 7.4$. 
These results agreed with that of Moustafine $e t$ $a l .{ }^{26}$ who found that, the release of diclofenac sodium from tablets containing chitosan Eudragit L 100 physical mixture was much slower compared with the corresponding IPC.

Furthermore, Conti et al. ${ }^{54}$, found that, the release rate of diltiazem hydrochloride is slower from tablets containing a mixture of sod. CMC and HPMC compared to that matrices containing the single polymers due to the interactions between sod. CMC and HPMC chains.

\section{Chitosan - pectin tablets}

Pectin tablets showed a higher drug release rate in acidic medium where the percent drug released was $75.6 \%$ after 6 hrs (Fig. 11), this may be due to high erosion rate of the tablets, moreover, pectin is converted to water insoluble pectinic acid in acidic medium which is expected to enhance tablet disintegration ${ }^{55}$.

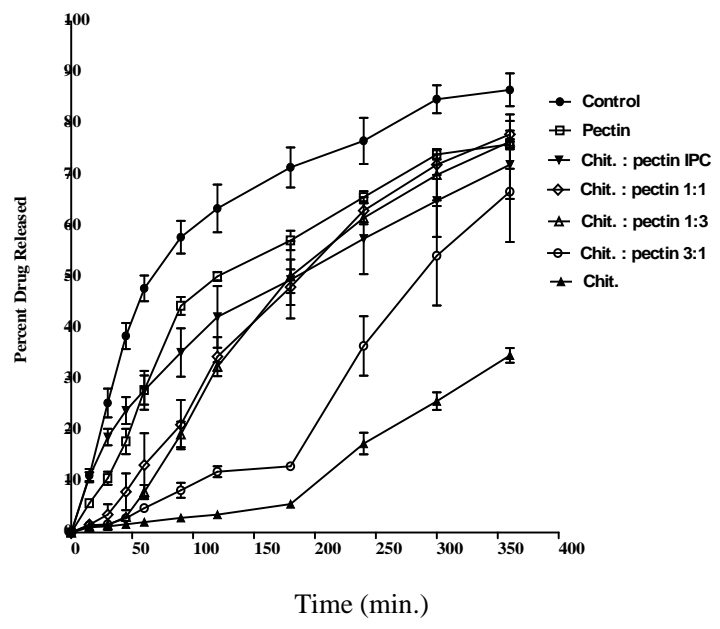

Fig. 11: In-vitro release profiles of ketoprofen from chitosan - pectin tablets in $0.1 \mathrm{~N} \mathrm{HCl}$ of $\mathrm{pH}$ 1.2 .

A comparison of the release profiles of ketoprofen from tablets containing chitosan pectin physical mixtures with that containing IPC in $0.1 \mathrm{~N} \mathrm{HCl}$ of $\mathrm{pH} 1.2$ (Fig. 11) revealed that, both the IPC and the physical mixtures $(1: 3 \& 1: 1)$ showed a rapid release rate of the drug. The percent drug released after $6 \mathrm{hrs}$ were $72,76.52$ and $77.96 \%$ from tablets containing chitosan - pectin IPC, physical mixtures of ratios $1: 3$ and $1: 1$, respectively. These results may be due to the erosion of these tablets followed by complete disintegration. So, each polymer remained alone and no IPC was formed. However, tablets containing chitosan - pectin physical mixture of ratio 3:1 produced slow release pattern in the first $3 \mathrm{hrs}$, then, disintegration of tablets occurred leading to increasing the percent drug released $(66.7 \%$ after $6 \mathrm{hrs})$.

The dissolution profiles of ketoprofen from chitosan - pectin tablets in phosphate buffer of $\mathrm{pH} 7.4$ are shown in figure 12. The percent drug released was $100 \%$ from pectin tablets after $5 \mathrm{hrs}$. It was reported that, drug release from pectin tablets depends on pectin hydrophilic character and hence, these tablets hydrated on exposure to dissolution medium, swelled and formed a gel layer. Then, drug release occurs by diffusion and erosion of this gel layer ${ }^{56}$.

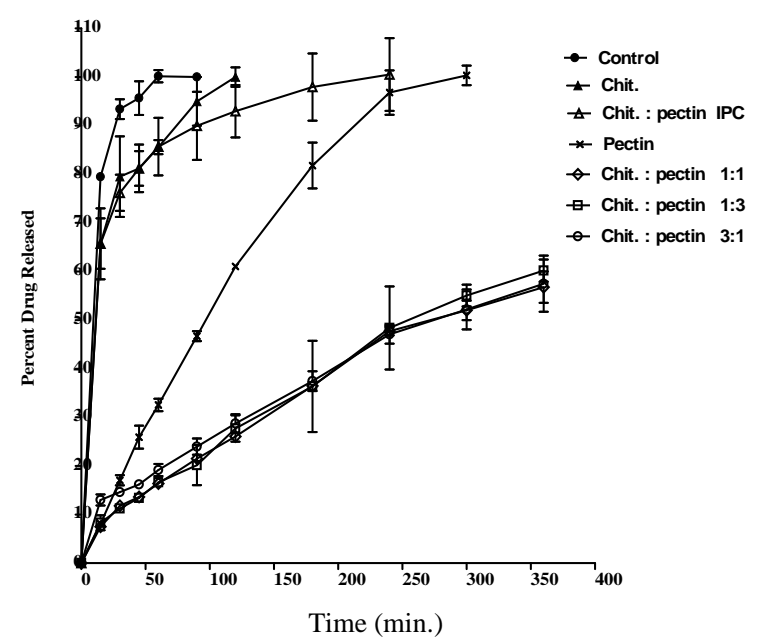

Fig. 12: In-vitro release profiles of ketoprofen from chitosan - pectin tablets in phosphate buffer of $\mathrm{pH} 7.4$.

On the other hand, tablets containing chitosan and pectin physical mixtures of different ratios significantly $(\mathrm{P}<0.0001)$ decreased the drug release rate compared to chitosan, pectin or IPC tablets and there was no significant difference between these ratios $(\mathrm{P})$ $0.05)$. This may be attributed to the interaction between chitosan and pectin at this $\mathrm{pH}$ during the dissolution process. Perugini et al. ${ }^{57}$ found that, fast drug release is obtained upon using pectin or chitosan alone as mucoadhesive formulations and to promote prolonged drug release in the small intestine, mixtures of chitosan and pectin have been used extensively as an IPC could develop as a consequence of ionic interactions between chitosan and pectin. 


\section{Kinetic release study}

The mechanism of drug release from tablets containing swellable polymers is complicated and not completely understood. Some systems may be classified as either diffusion or erosion controlled, while the most systems exhibit a combination of these mechanisms ${ }^{58}$. The release data of all tested formulae were mathematically analyzed according to Korsmeyer-Peppas semi-empirical model equation. The linearity in case of Korsmeyer-Peppas semi-empirical model was evaluated by calculating the linear correlation coefficient $\left(r^{2}\right)$, while, the release mechanism determined by evaluating the release exponent (n).

In $0.1 \mathrm{~N} \mathrm{HCl}$ of $\mathrm{pH} 1.2$, the tested tablet formulae showed correlation coefficient, $\mathrm{r}^{2}$, between 0.919 for chitosan - sod. alginate 1:1 tablets and 0.996 for chitosan - sod. alginate IPC tablets and the $\mathrm{n}$ values were ranged between 0.650 for chitosan - pectin 1:3 tablets and 0.943 for chitosan - sod. CMC 3:1 tablets (i.e. $0.5<\mathrm{n}<1$ ), indicating that, the release mechanism of ketoprofen from these matrices is an anomalous (non-Fickian) transport, which suggests that, both diffusion of the drug from the hydrated matrix and its own erosion modulate drug release ${ }^{59 \& 60}$.

In phosphate buffer of $\mathrm{pH} 7.4$, KorsmeyerPeppas semi-empirical model is not applied to chitosan, chitosan - sod. alginate and chitosan sod. CMC IPCs tablets due to their rapid release. Therefore, the release exponents for these formulae could not be calculated as a result of insufficient data points, up to $60 \%$ of the drug release profiles to provide accurate values. All other formulae have $(0.5<\mathrm{n}<1)$ that ranged between 0.501 for chitosan - pectin 3:1 tablets and 0.927 for chitosan - sod. alginate IPC tablets indicating that, the release mechanism of ketoprofen from these matrices is an anomalous (non-Fickian) transport. So, these tablets delivered their drug content by both diffusion and erosion mechanism.

\section{In-vivo study}

The mean plasma concentrations as a function of time for ketoprofen after oral administration of control tablets, chitosan - sod. CMC physical mixture in ratio of $1: 1$ and chitosan - sod. CMC IPC are illustrated in figure 13. From the obtained data, it could be observed that, there was a difference between the mean plasma concentrations as a function of time for ketoprofen after oral administration of the two tested formulae at all time intervals compared to the control tablet. Also, there was a noticeable difference in the $\mathrm{C}_{\max }$ and $\mathrm{T}_{\max }$ between the control and the tested formulae.

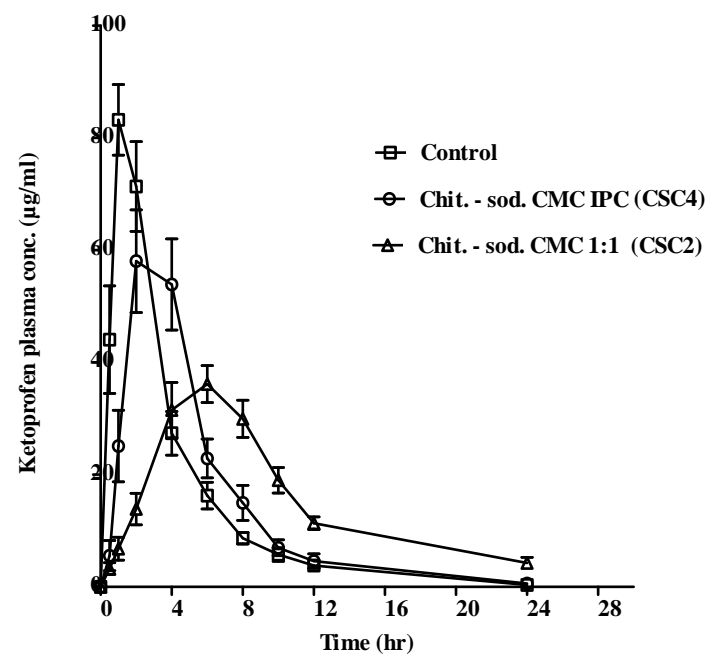

Fig. 13: Mean plasma concentration of ketoprofen after oral administration of control, chitosan - sod. CMC physical mixture 1:1 and chitosan - sod. CMC IPC tablets in rabbits.

The mean pharmacokinetic parameters of ketoprofen from different formulae represented by the value of $\mathrm{C}_{\max }(\mu \mathrm{g} / \mathrm{ml}), \mathrm{T}_{\max }(\mathrm{hr})$ and AUC ${ }_{0-24}\left(\mu \mathrm{g} . \mathrm{hr}_{\mathrm{m}} \mathrm{ml}^{-1}\right)$ are summarized in table 3. From the obtained results, it was evident that, the absorption of ketoprofen from the control tablets was rapid and reached its peak plasma concentration in $1.33 \pm 0.51 \mathrm{hrs}$, whereas, following oral administration of the tested formulae, chitosan - sod. CMC IPC (CSC4) and chitosan - sod. CMC physical mixture of ratio 1:1 (CSC2) tablets, the mean $\mathrm{T}_{\max }$ was $2.66 \pm 0.43$ and $5.66 \pm 0.81 \mathrm{hrs}$, respectively. While, the mean plasma concentrations $\left(\mathrm{C}_{\max }\right)$ were $62.34 \pm 5.02 \mu \mathrm{g} / \mathrm{ml}$ for CSC4 and $36.33 \pm 3.12 \mu \mathrm{g} / \mathrm{ml}$ for CSC2 compared to $84.28 \pm 5.14 \mu \mathrm{g} / \mathrm{ml}$ for the control tablets. These results showed that, the oral absorption of CSC 2 tablets leads to an increase of the mean $\mathrm{T}_{\max }$ and lowering the mean $\mathrm{C}_{\max }$ compared to CSC4 and control tablets and hence, indicated the delayed release behavior of $\mathrm{CSC} 2$ compared to $\mathrm{CSC} 4$ and control tablets. The mean $\mathrm{AUC}_{0-24}$ was found to be 
$341.98 \pm 17.88$ g.hr.ml ${ }^{-1}$ for CSC4 and 365.98 \pm 14.27 g.hr.ml ${ }^{-1}$ for CSC2 compared to $336.18 \pm 10.35$ g.hr.ml ${ }^{-1}$ for the control tablet.

Table 3: The mean pharmacokinetic parameters of ketoprofen from control, chitosan - sod. CMC physical mixture in ratio of 1:1 and chitosan - sod. CMC IPC tablets.

\begin{tabular}{|c|c|c|c|}
\hline Formulae & $\begin{array}{l}\text { Control } \\
\text { (L) }\end{array}$ & $\begin{array}{c}\text { Chitosan- } \\
\text { sod. CMC } \\
1: 1 \\
(\mathrm{CSC} 2)\end{array}$ & $\begin{array}{c}\text { Chitosan - } \\
\text { sod. CMC } \\
\text { IPC } \\
\text { (CSC4) }\end{array}$ \\
\hline $\mathrm{C}_{\max }(\mu \mathrm{g} / \mathrm{ml})$ & $\begin{array}{c}84.28 \pm \\
5.14\end{array}$ & $\begin{array}{c}36.33^{\mathrm{a}} \pm \\
3.12\end{array}$ & $\begin{array}{c}62.34^{\mathrm{a}} \pm \\
5.02\end{array}$ \\
\hline $\mathrm{T}_{\max }(\mathrm{hrs})$ & $\begin{array}{c}1.33 \pm \\
0.51\end{array}$ & $\begin{array}{c}5.66^{\mathrm{a}} \pm \\
0.81\end{array}$ & $\begin{array}{c}2.66^{\mathrm{b}} \pm \\
0.43\end{array}$ \\
\hline $\begin{array}{c}\mathrm{AUC}_{0-24} \\
\left(\mu \mathrm{g} \cdot \mathrm{hr} \mathrm{ml}^{-1}\right)\end{array}$ & $\begin{array}{c}336.18 \pm \\
10.35\end{array}$ & $\begin{array}{c}365.98^{\mathrm{b}} \pm \\
14.27\end{array}$ & $\begin{array}{c}341.98^{\mathrm{b}} \pm \\
17.88\end{array}$ \\
\hline
\end{tabular}

a Extremely significant from control $(\mathrm{p}<0.001)$. $b$ Non significant from control $(p>0.05)$.

The statistical analysis of the pharmacokinetic parameters of ketoprofen from different formulae revealed that, there was a significant difference between $\mathrm{CSC} 2$ tablets and each of the control and CSC4 tablets in the $\mathrm{C}_{\max }$ and $\mathrm{T}_{\max }$ values $(\mathrm{P}<0.001)$. Also, there was a significant difference between $\mathrm{C}_{\max }$ of CSC4 and the control tablets, however, their $\mathrm{T}_{\max }$ values were non significantly different $(\mathrm{P})$ $0.05)$. In addition, there was no significant difference between $\mathrm{CSC} 4, \mathrm{CSC} 2$ and the control tablets in the $\mathrm{AUC}_{0-24}$ values which indicated that, the absorption of ketoprofen was not influenced by the in-vivo behavior of the prepared tablets.

These findings achieved the goal of delayed release concept from tablets prepared using chitosan - sod. CMC physical mixture in ratio of 1:1 which has been estimated in reducing high peak plasma concentration $\left(\mathrm{C}_{\max }\right)$ and prolong the time required to reach maximum plasma concentration $\left(\mathrm{T}_{\max }\right)$. A similar finding was reported by Vergote $e t$ $a l^{61}$. They found that, the compression of pellets containing nanocrystalline or microcrystalline ketoprofen in combination with placebo wax/starch pellets resulted in sustaining the ketoprofen plasma concentrations as indicated by lowering $\mathrm{C}_{\max }$ and prolonging $\mathrm{T}_{\max }$.

\section{Conclusion}

The results of the present study confirmed the formation of an IPC between chitosan and anionic polymers as sod. alginate, sod. CMC or pectin. Tablets prepared using chitosan-sod. alginate and chitosan-pectin IPCs showed rapid drug release at $\mathrm{pH} 1.2$ and 7.4, however, chitosan-sod. CMC IPC tablets showed controlled drug release. On the other hand, tablets prepared using physical mixtures of chitosan with each of the previous anionic polymers showed in-situ IPC during dissolution process depending on the $\mathrm{pH}$ of the dissolution medium. So, a careful selection of IPC or polymers ratios in the physical mixture will be capable of producing systems which deliver drugs at different rates depending on the site of the dosage form within the GIT. The in-vivo study of tablets containing chitosan - sod. CMC physical mixture in ratio of 1:1 using rabbits showed that, these tablets were able to ensure controlled drug release for a longer period than that containing chitosan - sod. CMC IPC.

\section{REFERENCES}

1- E. Tsuchida and K. Abe, "Interactions between macromolecules in solution and intermacromolecular complexes", Adv. Polym. Sci., 45, 1-147 (1982).

2- B. Philipp, H. Dautzenberg, K. J. Linow, J. Koetz, and W. Dawydoff, "Polyelectrolyte complexes-recent developments and open problems", Progr. Polym. Sci., 14, 91-172 (1989).

3- J. Koetz, H. Koepke, G. Schmidt-Naake, and O. Vogl, "Polyanion-polycation complex formation as a function of the position of the functional groups", Polymer, 37, 2775-2781(1996).

4- S. Dumitriu and E. Chornet, "Inclusion and release of proteins from polysaccharide-based polyion complexes", Adv. Drug Deliv. Rev., 31, 223-246 (1998).

5- C. Tapia, Z. Escobar, E. Costa, J. S. Hagar, F. Valenzuela, C. Basualto, M. N. Gai, and M. Y. Pedram, "Comparative studies on polyelectrolyte complexes and mixtures of chitosan-alginate and chitosan-carrageenan as prolonged diltiazem clorhydrate release systems", 
Eur. J. Pharm. Biopharm., 57, 65-75 (2004).

6- R. I. Moustafine, I. M. Zaharov and V. A. Kemenova, "Physicochemical and drug release properties of Eudragit $^{\circledR} \mathrm{E}$ $\mathrm{PO} /$ Eudragit ${ }^{\circledR} \mathrm{L}$ 100-55 interpolyelectrolyte complexes", ibid., 63, 26-36 (2006).

7- M. G. Sankalia, R. C. Mashru, J. M. Sankalia and V. B. Sutariya, "Reversed chitosan-alginate polyelectrolyte complex for stability improvement of alphaamylase: Optimization and physicochemical characterization", ibid., 65, 215232 (2007).

8- M. Sivakumar, I. Manjubala and K. Rao, "Preparation, characterization and in-vitro release of gentamicin from coralline hydroxyapatite-chitosan composite microspheres", Carbohydr. Polym., 49, 281-288 (2002).

9- G. A. Abdelbary and M. I. Tadros, "Design and in-vitro / in-vivo evaluation of novel nicorandil extended release matrix tablets based on hydrophilic interpolymer complexes and a hydrophobic waxy polymer", Eur. J. Pharm. Biopharm., 69 (3), 1019-1028 (2008).

10- S. H. Park, M. K. Chun and H. K. Choi, "Preparation of an extended-release matrix tablet using chitosan/carbopol interpolymer complex", Int. J. Pharm., 347, 39-44 (2008).

11- K. Takayama, M. Hirata, Y. Machida, T. Masada, T. Sannan, and T. Nagai, "Effect of interpolymer complex formation on bioadhesive property and drug release phenomenon of compressed tablet consisting of chitosan and sodium hyaluronate", Chem. Pharm. Bull., 38, 1993- 1997 (1990).

12- H. J. Prado, M. C. Matulewicz, P. Bonelli and A. L. Cukierman, "Basic butylated methacrylate copolymer/kappacarrageenan interpolyelectrolyte complex: Preparation, characterization and drug release behaviour", Eur. J. Pharm. Biopharm., 70, 171-178 (2008).

13- K. S. Bhise, R. S. Dhumal, B. Chauhan, A. Paradkar and S. S. Kadam, "Effect of oppositely charged polymer and dissolution medium on swelling, erosion, and drug release from chitosan matrices", AAPS Pharm. Sci. Tech., 8 (2), Article 44 (2007).

14- Martindale, "The Complete Drug Reference", $35^{\text {th }}$ ed., Kathleen, P., Ed., The Pharmaceutical Press, London, U.K., 2007, pp. 1136- 1138.

15- M. J. Habib and R. Mesue, "Development of controlled release formulations of ketoprofen for oral use", Drug Dev. Ind. Pharm., 21, 1463-1472 (1995).

16- G. F. Palmieri, G. Bonacucina, P. D. Martino and S. Martelli, "Microencapsulation of semisolid ketoprofen/polymer microspheres", Int. J. Pharm., 242, 175-178 (2002).

17- A. Roda, L. Sabatini, M. Mirasoli, M. Baraldini and E. Roda, "Bioavailability of a new ketoprofen formulation for oncedaily oral administration", ibid., 241, 165172 (2002).

18- M. Üner, Ü. Gönüllü, G. Yener and T. Altınkurt, "A new approach for preparing a controlled release ketoprofen tablets by using beeswax", IL Farmaco, 60, 27-31 (2005).

19- M. H. Sabar, L. H. Samein and H. B. Sahib, "Some variables affecting formulation of ketoprofen sustained release oral tablet using polyelectrolyte complex as a matrix former", J. Pharm. and Allied Health Sciences, 1 (1), 1-15 (2011).

20- U.S.P., "The United States Pharmacopeia", 27 ${ }^{\text {th }}$ Revision, United States Pharmacopeial Convection Inc., The Broad of Trustees, Washington, U.S.A., 2004, pp. 170, 219, 2302, 2396.

21- R. W. Korsmeyer, R. Gurny, E. M. Doelker, P. Buri and N. A. Peppas, "Mechanism of solute release from porous hydrophilic Polymers", Int. J. Pharm., 15, 25-35 (1983).

22- S. Corveleyn, P. Deprez, G. Van der Weken, W. Baeyens and J. P. Remon, "Bioavailability of ketoprofen in horses after rectal administration", J. Vet. Pharmacol. Ther., 19, 359-363 (1996).

23- A. Mitrevej, N. Sinchaipanid, Y. Rungvejhavuttivittaya and $\mathrm{V}$. Kositchaiyong, "Multiunit controlledrelease diclofenac sodium capsules using complex of chitosan with sodium alginate 
or pectin", Pharm. Dev. Technol., 6 (3), 385-392 (2001).

24- K. Wang and Z. He, "Alginate-konjac glucomannan-chitosan beads as controlled release matrix", Int. J. Pharm., 244, 117126 (2002).

25- J. P. Soares, J. E. Santos, G. O. Chierice and E. T. G. Cavalheiro, "Thermal behavior of alginic acid and its sodium salt", Eclet. Quim., 29 (2), 57-64 (2004).

26- R. I. Moustafine, E. B. Margulis, L. F. Sibgatullina, V. A. Kemenova and G. Van den Mooter, "Comparative evaluation of interpolyelectrolyte complexes of chitosan with Eudragit L100 and Eudragit L100-55 as potential carriers for oral controlled drug delivery", Eur. J. Pharm. Biopharm., 70, 215-225 (2008).

27- S. Shu, X. Zhang, D. Teng, Z. Wang and C. Li, "Polyelectrolyte nanoparticles based on water-soluble chitosan-poly (L-aspartic acid)-polyethylene glycol for controlled protein release", Carbohydr. Res., 344, 1197-1204 (2009).

28- C. Rosca, M. I. Popa, G. Lisa and G. C. Chitanu, "Interaction of chitosan with natural or synthetic anionic polyelectrolytes, 1. The chitosan-carboxymethylcellulose complex", Carbohydr. Polym., 62, 35-41 (2005).

29- A. Ghaffari, K. Navaee, M. Oskoui, K. Bayati and M. Rafiee-Tehrani, "Preparation and characterization of free mixed-film of pectin/chitosan/Eudragit RS intended for sigmoidal drug delivery", Eur. J. Pharm. Biopharm., 67, 175-186 (2007).

30- S. S. Rashidova, R. Y. Milusheva, L. N. Semenova, M. Y. Mukhamedjanova, N. L. Voropaeva, S. asilyeva, R. Faizieva and I. N. Ruban, "Characteristics of interactions in the pectin-chitosan system", Chromatographia, 59, 779-782 (2004).

31- M. N. Khalid, F. Agnely, N. Yagoui, J. L. Grossiord and G. Couarraze, "Water sate characterization, swelling behavior, thermal and mechanical properties of chitosan based networks", Eur. J. Pharm. Sci., 15, 425-432 (2002).

32- O. Borges, G. Borchard, J. C. Verhoef, A. D. Sousa, and H. E. Junginger, "Preparation of coated nanoparticles for a new mucosal vaccine delivery system", Int. J. Pharm., 299, 155-166 (2005).

33- F. S. Kittur, K. V. Harish Prashanth, K. Udaya Sankar and R. N. Tharanathan, "Characterization of chitin, chitosan, and their carboxymethyl derivatives by differential scanning calorimetry", Carbohydr. Polym., 49, 185-193 (2002).

34- S. Despond, E. Espuche, N. Cartier and A. Domard, "Hydration mechanism of polysaccharides, A comparative study", J. Polymer Science, Part B: Polymer Physics, 43, 48-58 (2005).

35- M. J. Zohuriaan and F. Shokrolahi, "Thermal studies on natural and modified gums", Polymer Testing, 23 (5), 575-579 (2004).

36- T. Mimmo, C. Marzadori, D. Montecchio and C. Gessa, "Characterization of Caand Al-pectate gels by thermal analysis and FT-IR spectroscopy", Carbohydr. Res., 340 (16), 2510-2519 (2005).

37- J. Ostrowska-Czubenko and $\mathrm{M}$. Gierszewska-Druzyn'ska, "Effect of ionic crosslinking on the water state in hydrogel chitosan membranes", Carbohydr. Polym., 77, 590-598 (2009).

38- I. EL-Gibaly, "Oral delayed-release system based on Zn-pectinate gel (ZPG) microparticles as an alternative carrier to calcium pectinate beads for colonic drug delivery", Int. J. Pharm., 232, 199-211 (2002).

39- I. Henriksen, O. Skaugrud and J. Karlsen, "Use of chitosan malate as an excipient in wet granulation of three water soluble drugs", ibid., 98, 181-188 (1993).

40- T. Chandy and C. P. Sharma, "Chitosan as a biomaterial, Journal of Biomaterials", Artificial Cells \& Artificial Organs, 18 (1), 1-24 (1990).

41- G. A. F. Roberts, "Chitin Chemistry", The Mac Millan Press, London, 1992, pp. 1110, 274-315.

42- S. Goskonda and S. Upadrashta, "Avicel RC591/chitosan beads by extrusionspheronization technology", Drug. Dev. Ind. Pharm., 19, 915-927 (1993).

43- J. Kristl, J. Smid-Korbar, E. Struc, M. Schara and H. Rupprecht, "Hydrocolloids and gels of chitosan as drug carriers", Int. J. Pharm., 99, 13-19 (1993). 
44- M. Dentini, G. Rinaldi, A. Barbetta, D. Risica and G. Skjak-Braek, "Acid gel formation in (pseudo) alginates with and without $\mathrm{G}$ blocks produced by epimerizing mannuronan with C5 epimerases", Carbohydr. Polym., 63, 519-526 (2006).

45- K. Satoh, K. Takayama, Y. Machida, Y. Suzuki and T. Nagai, "Disintegration and dissolution characteristics of compressed tablets consisting of hydroxypropylcellulose and carboxyvinyl polymer", Chem. Pharm. Bull., 37 (6), 1642-1644, (1989).

46- M. L. Gonza'lez-Rodrı'guez, M. A. Holgado, C. Sa'nchez-Lafuente, A. M. Rabasco and A. Fini, "Alginate/chitosan particulate systems for sodium diclofenac release", Int. J. Pharm., 232, 225-234 (2002).

47- K. S. Bhise, R. S. Dhumal, B. Shailesh, A. R. Paradkar and S. S. Kadam, "Effect of Oppositely charged polymer and dissolution media on rheology of spraydried ionic complexes", AAPS Pharm. Sci. Tech., 11 (1), 226-232 (2010).

48- G. V. Betageri, D. V. Deshmukh and R. B. Gupta, "Oral sustained release bioadhesive tablet formulation of didanosine", Drug Dev. Ind. Pharm., 27, 129-136 (2001).

49- P. Sriamornsak and S. Sungthongjeen, "Modification of theophylline release with alginate gel formed in hard capsules", AAPS Pharm. Sci. Tech., 8 (3), Article 51 (2007).

50- C. Tapia, E. Costa, M. Moris, J. SapagHagar, F. Valenzuela and C. Basualto, "Study of the influence of the $\mathrm{pH}$ media dissolution, degree of polymerization and degree of swelling of the polymers on the mechanism of release of diltiazem from matrices based on mixtures of chitosan/alginate", Drug Dev. Ind. Pharm., 28, 217-224 (2002).

51- A. H. EL-Kamel, M. S. Sokar, V. F. Naggar and S. S. AL Gamal, "Bioadhesive controlled release metronidazole vaginal tablets", Acta Pharm., 52, 171-179 (2002a).

52- Y. Sawayanagi, N. Nambu and T. Nagai, "Use of chitosan for sustained release preparations of water soluble drugs", Chem. Pharm. Bull., 30, 4213-4215 (1982).
53- A. H. EL-Kamel, M. S. Sokar, V. F. Naggar and S. S. Al-Gamal, "Chitosan and sodium alginate based bioadhesive vaginal tablets", AAPS Pharm. Sci. Tech., 4 (4) Article 44 (2002b).

54- S. Conti, L. Maggia, L. Segalea, E. Ochoa Machiste, U. Conte, P. Grenier and G. Vergnault, "Matrices containing sodium CMC and HPMC, I. Dissolution performance characterization", Int. J. Pharm., 333, 136-142 (2007).

55- A. B. Bangudu and N. Pilpel, "Effects of interacting variables on the tensile strengths and disintegration times of paracetamol tablets", J. Pharm. Pharmacol., 37, 903-905 (1985).

56- M. Turkoglu and T. Ugurlu, "In-vitro evaluation of pectin-HPMC compression coated 5-aminosalicylic acid tablets for colonic delivery", Eur. J. Pharm. Biopharm., 53, 65-73 (2002).

57- P. Perugini, I. Genta, B. Conti, T. Modena and F. Pavanetto, "Periodontal delivery of ipriflavone: new chitosan/PLGA film delivery system for a lipophilic drug", Int. J. Pharm., 252, 1-9 (2003).

58- J. Siepmann and N. A. Peppas, "Modeling of drug release from delivery systems based on hydroxypropyl methyl cellulose", Adv. Drug deliv. Rev., 48, 139-157 (2001).

59- N. A. Peppas, "Analysis of Fickian and non-Fickian drug release from polymers", Pharm. Acta Helv., 60, 110-111 (1985).

60- N. A. Peppas and R. W. Korsmeyer, "Dynamically Swelling Hydrogels in Controlled Release Applications", In: "Hydrogels in Medicine and Pharmacy", $3^{\text {rd }}$ ed., Peppas N. A., Ed., CRC Press, Boca Raton, U.S.A., 1986, pp. 109-136.

61- G. J. Vergote, C. Vervaet, I. Van Driessche, S. Hoste, S. De Smedt, J. Demeester, R. A. Jain, S. Ruddy and J. P. Remon, "In-vivo evaluation of matrix pellets containing nanocrystalline ketoprofen", Int. J. Pharm., 240, 79-84 (2002). 